\title{
Strength Properties of High-Strength Concrete Containing Coal Bottom Ash as a Replacement of Aggregates
}

\author{
In-Hwan Yang $\mathbb{D},{ }^{1}$ Jihun Park, ${ }^{1}$ Nhien Dinh Le, ${ }^{1}$ and Sanghwa Jung ${ }^{2}$ \\ ${ }^{1}$ Department of Civil Engineering, Kunsan National University, Daehak-ro 558, Kunsan, Jeonbuk 54150, Republic of Korea \\ ${ }^{2}$ Korea Conformity Laboratories, Seoul 08503, Republic of Korea \\ Correspondence should be addressed to In-Hwan Yang; ihyang@kunsan.ac.kr
}

Received 17 March 2020; Revised 2 June 2020; Accepted 3 June 2020; Published 23 June 2020

Guest Editor: Nadezda Stevulova

Copyright ( $\odot 2020$ In-Hwan Yang et al. This is an open access article distributed under the Creative Commons Attribution License, which permits unrestricted use, distribution, and reproduction in any medium, provided the original work is properly cited.

Most previous studies on the strength properties of coal bottom ash (CBA) concrete have focused on concrete with a normal compressive strength, and thus, studies on the strength properties of high-strength concrete (HSC) containing CBA are limited. Therefore, the effects of replacing fine aggregates with CBA and variations in the curing age on the strength properties of HSC with a compressive strength of greater than $60 \mathrm{MPa}$ were investigated in this study. The different CBA contents included 25, 50, 75, and $100 \%$, and the different curing ages were 28 and 56 days. The mechanical properties of the HSC with CBA incorporated as fine aggregates were examined. The experimental results revealed that CBA could be partially or totally substituted for fine aggregates during HSC production. The test results also showed that the compressive, splitting tensile, and flexural strengths of the HSC containing CBA fine aggregates slightly decreased as the CBA content increased. Moreover, useful relationships between the compressive strength, splitting tensile strength, and flexural strength were suggested, and the predictions reasonably agreed with the measurements. Compared to those of the control specimen, the pulse velocities of the HSC specimens at various CBA contents decreased by less than $3 \%$. In addition, equations for predicting the strength values of CBA concrete by using the ultrasonic pulse velocity were suggested.

\section{Introduction}

Coal bottom ash (CBA) is an industrial waste produced at the bottom of coal furnaces in thermal power plants [1-5]. Gollakota et al. [6] indicated that ash ponds or lagoons have caused numerous ecological problems and severe distress to local communities due to their increasing landfill space and escalating disposal costs. Therefore, CBA utilization is the best way to minimize the environmental concern of CBA and also conserves natural resources [7-9]. CBA was recently applied in several fields, especially in the construction industry [10-14].

The recycling rate of CBA in Korea was $7.1 \%, 11.3 \%$, $14.6 \%, 17.3 \%$, and $23.4 \%$, respectively, in 2014 through 2018 [15]. Thus, the recycling rate of CBA in Korea has gradually increased over the past 4 years. In addition, according to a report [13] about recycling coal bottom ash, approximately
$5 \%$ and $21 \%$ of the CBA were utilized as aggregate in mortar and concrete in the US and EU, respectively.

Moreover, CBA was recently used in the mixture of normal vibrating concrete and self-compacting concrete because the sizes of CBA and natural fine aggregate are similar and due to the pozzolanic activity of the CBA [11]. Several studies [16-22] actually reported that fine aggregates could be replaced by CBA in concrete fabrication. Singh et al. [16] reviewed the effect of using CBA as a natural fine aggregate replacement on the properties of normally vibrated and self-compacting concrete. This review reported that most of the compressive strength results of previous studies slightly decreased with increasing CBA contents, whereas some cases showed a high compressive strength at low replacement levels. Singh and Siddique [23] also implemented experimental tests to evaluate the strength properties of CBA concrete, which revealed that the compressive strengths of 
CBA concrete at the different curing days were insignificantly reduced by using the CBA.

Regarding the tensile strength and flexural strength of conventional concrete containing CBA, test results in previous studies [24-27] showed that using CBA to replace fine aggregates decreased the splitting tensile strength and flexural strength of CBA concrete. Ngohpok et al. [26] estimated the mechanical properties of pervious concrete containing recycled concrete and bottom ash aggregates. The splitting tensile strength and flexural strength decreased as the recycled concrete and bottom ash aggregate contents increased. Ibrahim et al. [28] also investigated the utilization of CBA in self-compacting concrete. They showed that the greatest tensile strength of the self-compacting concrete containing $\mathrm{CBA}$ was $3.28 \mathrm{MPa}$, when fine aggregate was replaced by $10 \% \mathrm{CBA}$.

Due to the development of construction technology, high-strength concrete (HSC) has become commercially available [29-31]. However, most studies on the material properties of CBA concrete have focused on the strength properties of conventional concrete with a compressive strength of less than $40 \mathrm{MPa}$. Recently, Kim and Lee [32] investigated the influences of replacing fine and coarse aggregates with power bottom ash on the mechanical properties of HSC. This study reported that substituting CBA for natural fine and coarse aggregates affected the flexural strength more significantly than the compressive strength of the HSC. CBA utilization for HSC is still limited; therefore, experimental research on HSC with fine aggregates partially or fully replaced by CBA is essential.

In this study, the strength properties of concrete specimens with natural fine aggregates partially or fully replaced by CBA aggregates $(25,50,75$, and $100 \%)$ and with a compressive strength of greater than $60 \mathrm{MPa}$ were investigated. For fresh concrete, a slump test was performed to examine the workability of the CBA concrete. For hardened concrete, the unit weight, compressive strength, tensile strength, flexural strength, and ultrasonic pulse velocity were investigated at different curing ages of 28 and 56 days. Finally, the relationships between the compressive strength, tensile strength, and flexural strength and the ultrasonic pulse velocity of the CBA concrete specimens were proposed.

\section{Experimental Program}

2.1. Aggregates. The natural fine and coarse aggregates used in this study were crushed, but the source of each aggregate was different. The natural fine aggregates are shown in Figure 1(a). The particle size distribution of the natural fine aggregates is shown in Figure 2. The maximum size of the natural coarse aggregates used in this study was $20 \mathrm{~mm}$. The density and water absorption results of the natural fine and coarse aggregates are also shown in Table 1. The densities of the natural fine and coarse aggregates were 2.60 and $2.61 \mathrm{~g} / \mathrm{cm}^{3}$, respectively.

The CBA used in this study was collected from a thermal power plant company. The CBA fine aggregates, which passed through a $5.0 \mathrm{~mm}$ sieve and remained on a $0.15 \mathrm{~mm}$ sieve, were applied to fabricate the concrete. The CBA used for this study is presented in Figure 1(b), and the particle size distribution of the CBA is also presented in Figure 2. The test results of the density and water absorption of the CBA are shown in Table 1 . The test results indicated that the density of the CBA was smaller than that of natural fine aggregates. However, the water absorption of the bottom ash of $6.87 \%$ was approximately 10 times higher than that of the crushed fine aggregate of $0.69 \%$. Additionally, the fineness modulus of the CBA was 3.83, whereas that of the fine aggregates was 3.17. The chemical compositions derived from energy dispersive spectrometry (EDS) analysis of the CBA are shown in Table 2. The CBA used in this study was mainly composed of $\mathrm{SiO}_{2}$ (62.94\%), $\mathrm{Al}_{2} \mathrm{O}_{3}$ (18.09\%), and $\mathrm{Fe}_{2} \mathrm{O}_{3}$ (9.95\%), and the total amount of these compositions was $90.98 \%$. The minor compositions included $\mathrm{CaO}$ and $\mathrm{Na}_{2} \mathrm{O}$. Figure 3 shows the scanning electron microscopy (SEM) and EDS analysis results. The shape of the CBA is complex and irregular. In addition, there are small voids with different sizes in the CBA.

2.2. Mix Proportions. A concrete mix with a target compressive strength of $60 \mathrm{MPa}$ at a curing age of 28 days was designed. The constituent materials used in the production of the control concrete and the CBA concrete are indicated in Table 3. There are five different mixtures of concrete with various percentages of CBA as fine aggregates.

In previous studies [18-20], the water-cement ratio ranged from 0.45 to 0.6 , when the compressive strengths were less than $40 \mathrm{MPa}$, and also, the compressive strengths of the concrete gradually reduced as the water-cement ratio increased. Moreover, for a high-strength concrete mixture, a high water content is not recommended because unbound water may result in pores inside the concrete and cause the concrete to shrink, which adversely affects the compressive strength of concrete. Accordingly, in this study, the high compressive strength of CBA concrete could be achieved with a low water-cement ratio. A water-cement ratio of 0.3 was used in all the concrete mixtures in this study. This water-cement ratio was much less than that of the previous studies.

In addition to the control concrete mixture, for each mixture, CBA replaced $25,50,75$, and $100 \%$ of the natural fine aggregates by volume in the concrete. The unit contents of cement and natural coarse aggregates were fixed at $595.0 \mathrm{~kg} /$ $\mathrm{m}^{3}$ and $878.5 \mathrm{~kg} / \mathrm{m}^{3}$, respectively, when fabricating all the mixtures. Ordinary Portland cement (OPC) was used as the basic binder. A high water-reducing agent (HWRA) with a unit content of $3.6 \mathrm{~kg} / \mathrm{m}^{3}$, which corresponded to $0.6 \%$ OPC by weight, was used to enhance the workability of the CBA concrete at a low water-cement ratio. The CBA concrete mixtures were designated M00, M25, M50, M75, and M100, in which the number in each mixture label represents the percentage of the fine aggregates replaced by CBA.

2.3. Casting and Curing the Specimens. Cylindrical specimens with dimensions of $100 \mathrm{~mm} \times 200 \mathrm{~mm}$ were cast to measure the unit weight, compressive strength, and splitting 


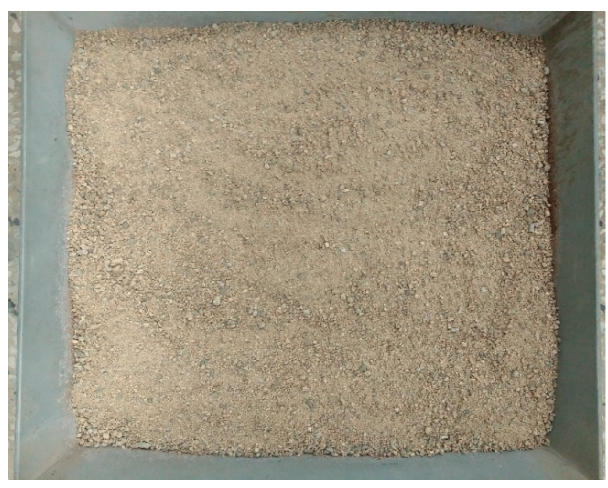

(a)

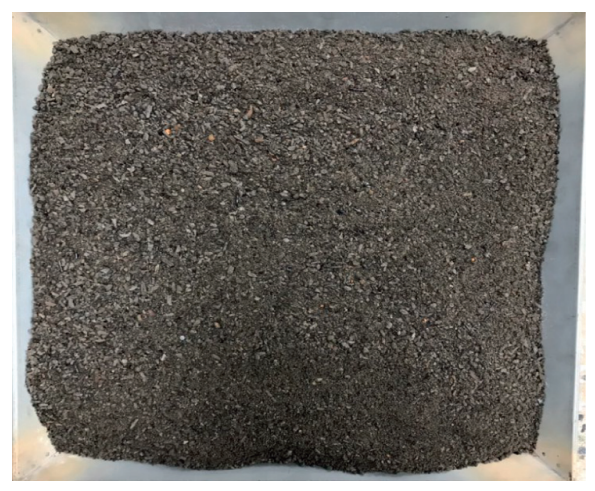

(b)

Figure 1: Natural fine aggregates and CBA aggregates. (a) Natural fine aggregates. (b) CBA aggregates.

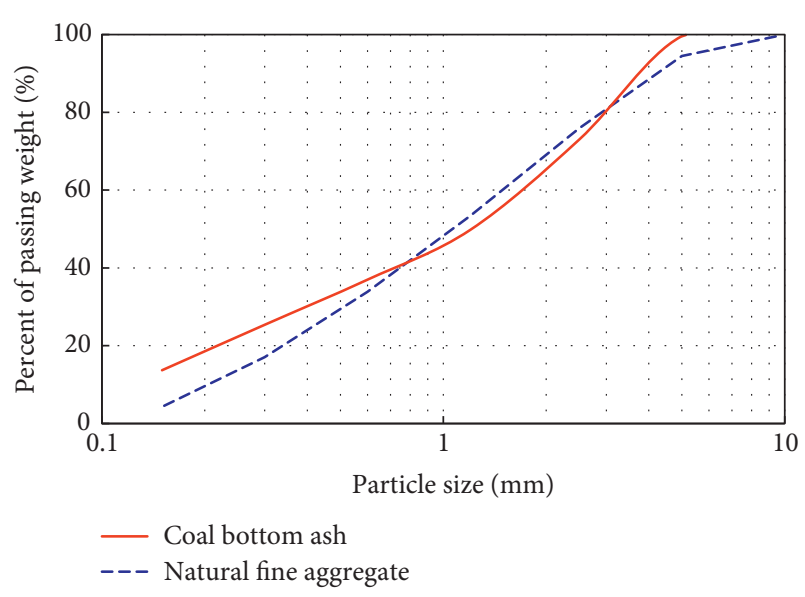

FIGURE 2: Grading curves of the CBA and natural fine aggregates.

tensile strength of the CBA concrete, and prism specimens with dimensions of $100 \mathrm{~mm} \times 100 \mathrm{~mm} \times 400 \mathrm{~mm}$ were fabricated to measure the flexural strength of the concrete. As soon as the specimens were cast, they were covered with plastic wrap and moist-cured for one day after casting. Then, the specimens were demolded at a curing age of $24 \pm 1$ hour and then cured in the water tank at $23 \pm 2^{\circ} \mathrm{C}$ until the specified testing age.

2.4. Test Procedure. For the fresh concrete, a slump test was performed to examine the workability of the concrete. For the hardened concrete, the unit weight, compressive strength, splitting tensile strength, flexural strength, and ultrasonic pulse velocity of the concrete were measured at curing ages of 28 and 56 days. The compressive strength of the CBA concrete specimens was measured by testing cylindrical specimens with a hydraulic testing machine in accordance with the KS F 2405 test method [33]. The splitting tensile strength test was also determined by testing cylindrical specimens in accordance with the KS F 2423 test method [34]. The flexural strength of the CBA concrete was measured by testing prism specimens under four-point loading in accordance with the KS F 2408 test method [35]. The average values of the three specimens were recorded to obtain the mechanical properties of the concrete.

An ultrasonic pulse velocity test was also implemented, and the test results were used to estimate the uniformity and relative quality of the CBA concrete. The ultrasonic pulse velocity tests conformed to the ASTM C597-09 test method [36]. Three cylindrical specimens of each mixture were prepared, and both ends of each specimen were polished to ensure flat contact between the transducers and end surfaces of the specimen. Moreover, to achieve accurate pulse travel time measurements, the applied frequency of the transducers was $54 \mathrm{kHz}$. During this test, one transducer was held on the surface of a cylindrical specimen, which transmitted pulses of compressional waves through the concrete specimen. These pulses were received and converted into electrical energy by another transducer, which was held on another surface of the concrete specimen.

\section{Test Results and Discussions}

Concrete applications in the construction industry may be considered in terms of two concrete properties. One is the mechanical properties of the concrete, and the other is the durability of the concrete. This study investigated the mechanical properties of HSC including CBA, but the concrete durability was beyond the scope of this study.

3.1. Workability. The workability of the fresh CBA concrete was determined by performing a slump test. The test results are shown in Figure 4. The slump of the CBA concrete mixtures declined as the crushed fine aggregate replacement by CBA increased. The slumps of CBA concrete mixtures M25, M50, M75, and M100 were 75, 70, 67.5, and $45 \mathrm{~mm}$, respectively, whereas that of the control concrete mixture was $80 \mathrm{~mm}$. The reduction in the workability of CBA concrete was caused by the increase in surface area and the irregular shapes of the CBA particles. In addition, utilization of CBA as fine aggregates enhanced the concrete texture, which had more irregular and porous particles than the control concrete. For that reason, the interparticle friction increased, which led to an obstruction of the workability of the fresh concrete. The test results in this study are 
TABle 1: Physical properties of the CBA, natural fine, and coarse aggregates.

\begin{tabular}{lccc}
\hline Material & Density $\left(\mathrm{g} / \mathrm{cm}^{3}\right)$ & Water absorption (\%) & Fineness modulus \\
\hline Natural fine aggregates & 2.60 & 0.69 & 3.17 \\
Natural coarse aggregates & 2.61 & 1.44 & 6.77 \\
CBA & 1.84 & 6.87 & 3.83 \\
\hline
\end{tabular}

TABle 2: Chemical composition of the CBA.

\begin{tabular}{lc}
\hline Compound & CBA (\%) \\
\hline $\mathrm{SiO}_{2}$ & 62.94 \\
$\mathrm{Al}_{2} \mathrm{O}_{3}$ & 18.09 \\
$\mathrm{Fe}_{2} \mathrm{O}_{3}$ & 9.95 \\
$\mathrm{CaO}$ & 5.08 \\
$\mathrm{Na}_{2} \mathrm{O}$ & 1.58 \\
$\mathrm{~K}_{2} \mathrm{O}$ & 0.99 \\
$\mathrm{MgO}$ & 1.37 \\
\hline
\end{tabular}

comparable to those reported by Singh and Siddique [20]. Their test results indicated that the water demand of CBA concrete increased to attain the same slump values as control concrete and that the water requirement decreased, when a water-reducing admixture was used.

3.2. Unit Weight. The unit weight test results of the concrete specimens with different CBA contents are presented in Figure 5. This figure shows that the unit weights of the concrete decreased as the CBA content increased. At a curing age of 28 days, the unit weight of CBA concrete mixtures M25, M50, M75, and M100 slightly decreased by 2.1, 3.2, 5.3, and $7.6 \%$ compared to that of the control concrete mixture $\left(2370.2 \mathrm{~kg} / \mathrm{m}^{3}\right)$, respectively. At a curing age of 56 days, the unit weight of the CBA concrete mixtures M25, M50, M75, and M100 decreased by 2.0, 3.7, 5.8, and 6.7\% compared to that of the control concrete mixture $\left(2386.5 \mathrm{~kg} / \mathrm{m}^{3}\right)$, respectively. The decline in the unit weight of the CBA concrete mixtures might be attributed to the smaller density of the CBA aggregate compared to that of natural fine aggregates. Hence, the CBA aggregates play the role of lightweight aggregates rather than conventional crushed aggregates.

The unit weights of the concrete specimens with different curing ages are also shown in Figure 5. When the curing age increased from 28 to 56 days, the unit weights of the concrete with $0,25,50,75$, and $100 \%$ replacement of crushed fine aggregate by CBA insignificantly increased by $0.7,0.9,0.2$, 0.1 , and $1.6 \%$, respectively. With the interaction of the chemical components of the CBA with cement paste, the concrete matrix at a curing age of 56 days was slightly more packed than that at a curing age of 28 days. That was why the unit weight of the CBA concrete increased slightly with increasing curing age.

3.3. Compressive Strength. The compressive strength test results of concrete specimens with different CBA contents are presented in Figure 6. At a curing age of 28 days, the overall compressive strength of the CBA mixtures decreased as the CBA content increased. The compressive strength of CBA concrete mixture M25 increased insignificantly by $1.2 \%$ in comparison to that of the control concrete mixture (69.4 MPa). In contrast, the compressive strength values of CBA concrete mixtures M50, M75, and M100 declined by 3.0, 4.6, and 8.8\% compared to that of the control concrete mixture, respectively. At a curing age of 56 days, the compressive strength values of CBA concrete mixtures M25, M50, M75, and M100 declined by 2.0,3.0, 4.8, and $6.2 \%$ compared to that of the control concrete mixture $(76.7 \mathrm{MPa})$, respectively. The decline in the compressive strengths of the CBA concrete can be explained by the increase in the porosity in the concrete because the pores in the CBA concrete cause a negative influence on the compressive strength of the concrete specimens. The test results in this study were comparable with the previous experimental studies reported by Muthusamy et al. [37] and Abdulmatin et al. [3]. In their studies, the incorporation of CBA aggregates instead of natural fine aggregates had an adverse effect on the compressive strength of concrete at a curing age of 28 days. The substitution of stronger materials (natural aggregates) by weaker materials (CBA) was the factor causing the decline in the compressive strength of the concrete specimens.

Moreover, the compressive strength values of the CBA concrete in all mixtures exceeded $60 \mathrm{MPa}$, which could be regarded as HSC. The test results in this study implied that CBA could be used for the fabrication of HSC.

The long-term strength of CBA concrete may be higher than that of control concrete because of the pozzolanic activity of the CBA [3, 38]. For example, Abdulmatin et al. [3] showed that the compressive strength of a CBA mortar increased by $16.1-26.8 \%$, when the curing ages increased from 28 to 90 days, whereas the compressive strength of the control mortar increased by $17.7 \%$, when the curing ages increased from 28 to 90 days. However, in this study, the effect of curing for only 28 and 56 days on the strengths of CBA concrete was investigated, because the strengths at these curing ages are usually considered when designing concrete structures.

The compressive strength values of the concrete specimens with different curing ages are also shown in Figure 6. When the curing ages increased from 28 to 56 days, the compressive strength values of the concrete with $0,25,50$, 75 , and $100 \%$ replacement of fine aggregates by CBA increased by $10.4,6.9,10.4,10.2$, and $13.6 \%$, respectively. The substantial increase in the compressive strength of the CBA concrete mixtures at a curing age of 56 days was due to the pozzolanic activity of the CBA. For the CBA concrete with a longer curing age, calcium hydroxide begins to react with the CBA particles and create calcium silicate hydrate (C-S-H) gel [23]. With increasing curing age, calcium silicates and aluminates are formed by the reaction between reactive silica in the CBA and alkali calcium hydroxide from the hydration of cement. These calcium silicates and aluminates fill the voids in the interfacial transition zone and enhance the compressive strength. 


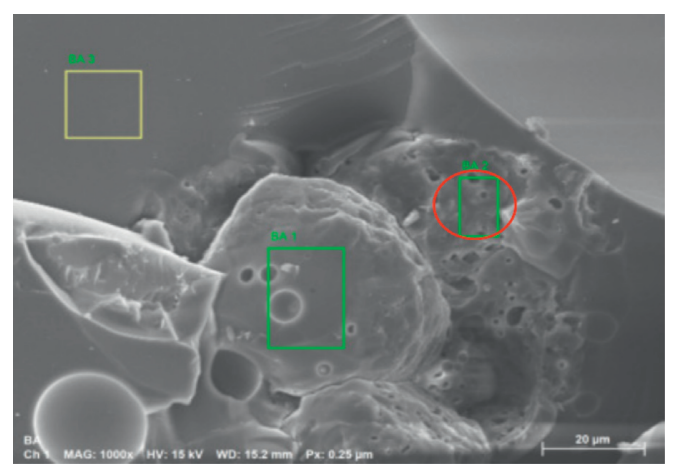

(a)

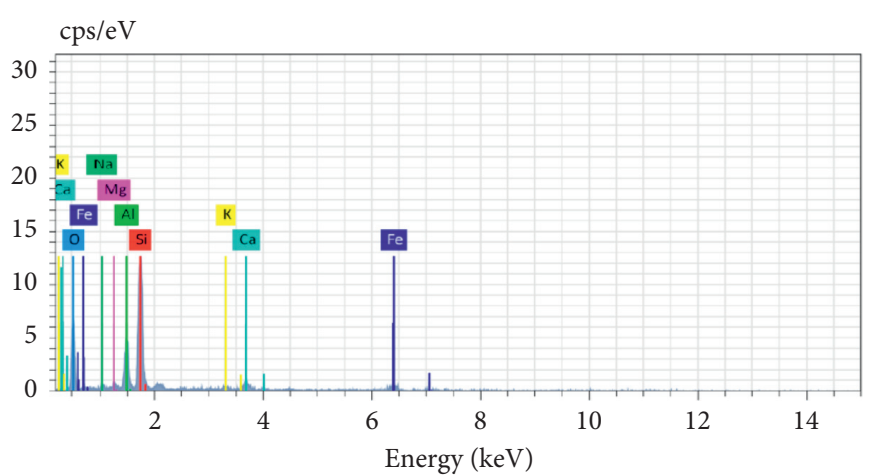

(b)

FIGURE 3: SEM and EDS results of the CBA. (a) SEM morphology of the CBA. (b) EDS spectra of the CBA (at the red circle in (a)).

TABle 3: Mixing proportions of the CBA concrete.

\begin{tabular}{|c|c|c|c|c|c|c|c|c|}
\hline \multirow[b]{2}{*}{ Mixture } & \multirow[b]{2}{*}{$\begin{array}{c}\text { Replacement of fine aggregates } \\
\text { with CBA (\%) }\end{array}$} & \multirow[b]{2}{*}{$\mathrm{W} / \mathrm{C}$} & \multirow[b]{2}{*}{ Water } & \multicolumn{5}{|c|}{ Unit content $\left(\mathrm{kg} / \mathrm{m}^{3}\right)$} \\
\hline & & & & $\begin{array}{l}\text { Cement } \\
(\mathrm{OPC})^{\mathrm{a}}\end{array}$ & $\begin{array}{l}\text { Natural coarse } \\
\text { aggregates }\end{array}$ & $\begin{array}{l}\text { Natural fine } \\
\text { aggregates }\end{array}$ & $\mathrm{CBA}$ & $\begin{array}{c}\operatorname{HWRA}^{\mathrm{b}}(0.6 \% \times \\
\text { cement })\end{array}$ \\
\hline M00 & 0 & 0.3 & 178.5 & 595.0 & 878.5 & 663.0 & 0.0 & 3.6 \\
\hline M25 & 25 & 0.3 & 178.5 & 595.0 & 878.5 & 497.2 & 117.7 & 3.6 \\
\hline M50 & 50 & 0.3 & 178.5 & 595.0 & 878.5 & 331.5 & 235.3 & 3.6 \\
\hline M75 & 75 & 0.3 & 178.5 & 595.0 & 878.5 & 165.7 & 353.0 & 3.6 \\
\hline M100 & 100 & 0.3 & 178.5 & 595.0 & 878.5 & 0.0 & 470.7 & 3.6 \\
\hline
\end{tabular}

${ }^{\mathrm{a} O P C}$ : ordinary Portland cement. ${ }^{\mathrm{b}} \mathrm{HWRA}$ : high water-reducing agent.

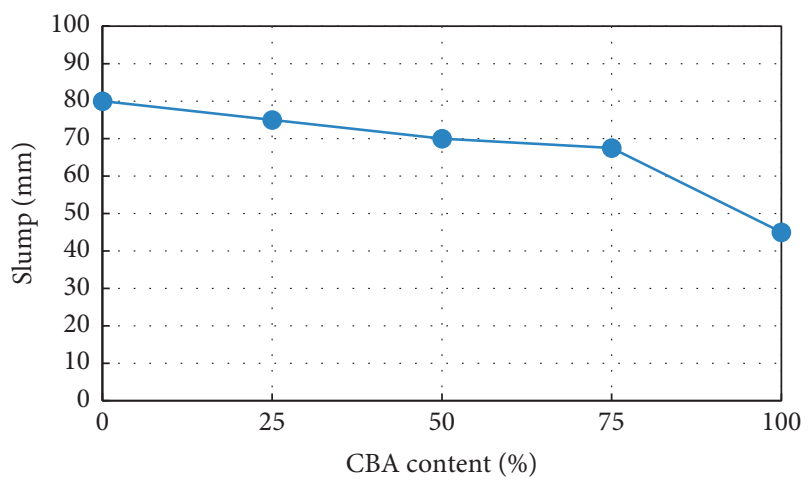

Figure 4: Effect of the CBA on the slump of the concrete.

3.4. Splitting Tensile Strength. The splitting tensile strength values of the concrete specimens with different $\mathrm{CBA}$ contents are shown in Figure 7. The tendency of the tensile strength test results with the increase in the CBA contents was less clear than that of the compressive strength. At a curing age of 28 days, the splitting tensile strength of the CBA concrete mixtures including 25\% CBA as fine aggregates was $15.8 \%$ lower than that of the control concrete mixture. However, the splitting tensile strength values of the CBA concrete mixtures incorporating 50,75, and $100 \%$ CBA as fine aggregates were 9.7, 4.0, and $17.2 \%$ lower than that of the control concrete mixture, respectively. At a curing age of 56 days, the splitting tensile strengths of the concrete mixtures incorporating $25,50,75$, and $100 \% \mathrm{CBA}$ as fine

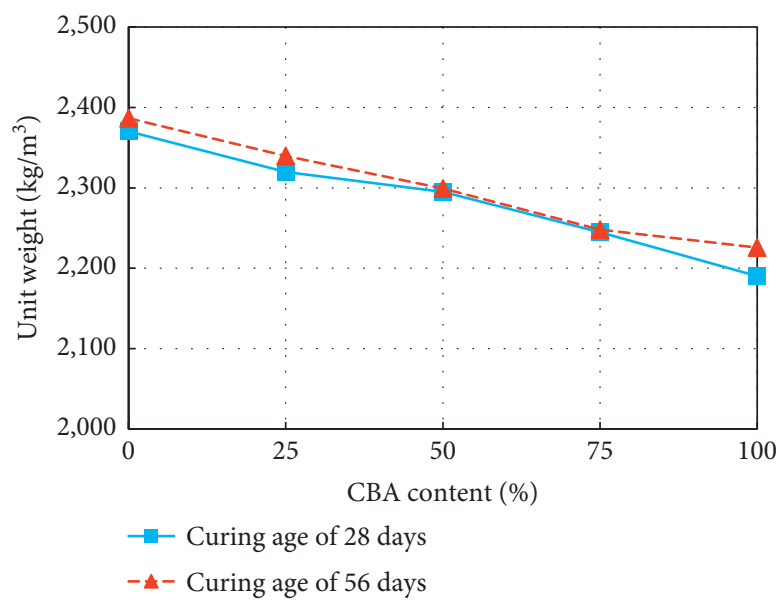

FIGURE 5: Unit weight test results.

aggregates were $6.8,7.4,6.4$, and $4.9 \%$ lower than that of the control concrete mixture, respectively. The splitting tensile strength difference between the CBA concrete and the control concrete became less distinct at a curing age of 56 days than at 28 days. The decrease in the splitting tensile strength with increasing CBA content was due to the increase in the volume of pores in the concrete gained by replacing the fine aggregates with CBA.

In addition, the splitting tensile strength of each mixture exceeded $4 \mathrm{MPa}$. This meant that the splitting tensile strength of HSC containing CBA as fine aggregates in this 


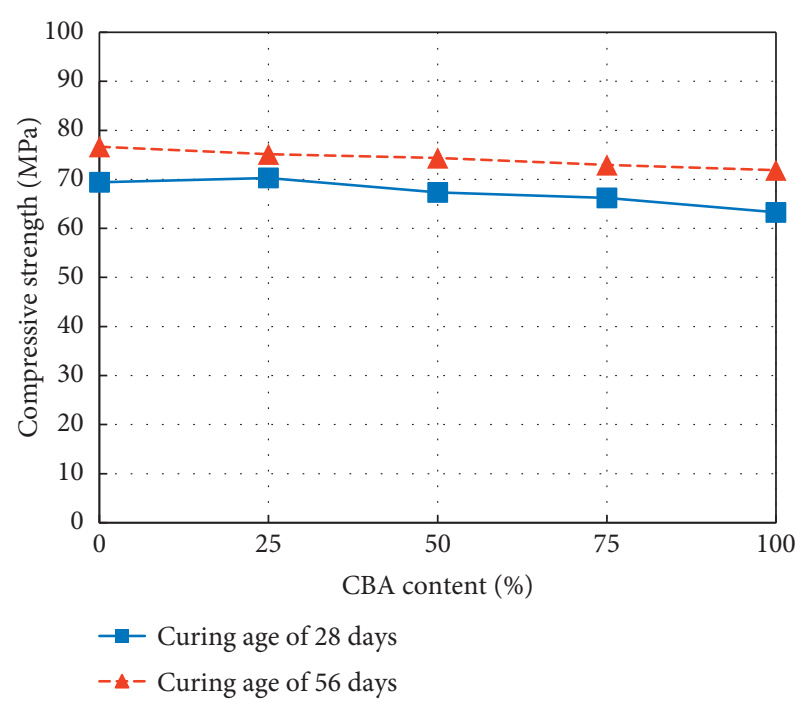

Figure 6: Compressive strength test results.

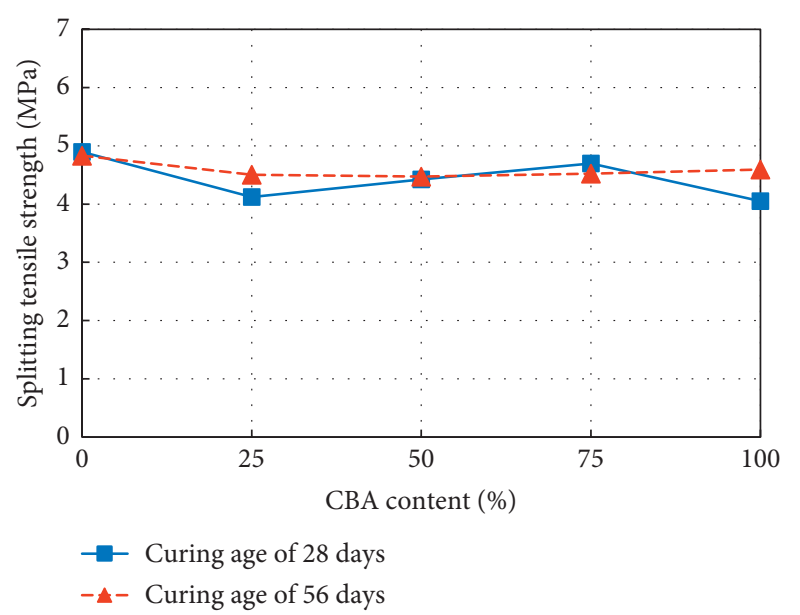

Figure 7: Splitting tensile strength test results.

study would be comparable to that of conventional normalstrength concrete containing natural aggregates.

The splitting tensile strength values of the concrete specimens with different curing ages are also shown in Figure 7 . When the curing age increased from 28 to 56 days, the tensile strengths of concrete with the substitution of 0 and $75 \%$ of CBA as fine aggregates decreased by 1.3 and $3.8 \%$, respectively, whereas the tensile strength values of the concrete with 25,50 , and $100 \%$ replacement of fine aggregates by CBA increased by $9.2,1.1$, and $13.4 \%$, respectively.

3.5. Flexural Strength. The flexural strength test results with different CBA contents are shown in Figure 8. At a curing age of 28 days, the flexural strength values of the CBA concrete mixtures incorporating 25, 50, 75, and 100\% CBA as fine aggregates were reduced by $1.0,4.6,7.3$, and $17.1 \%$ in comparison with that of the control mixture $(6.6 \mathrm{MPa})$, respectively. At a curing age of 56 days, the flexural strength

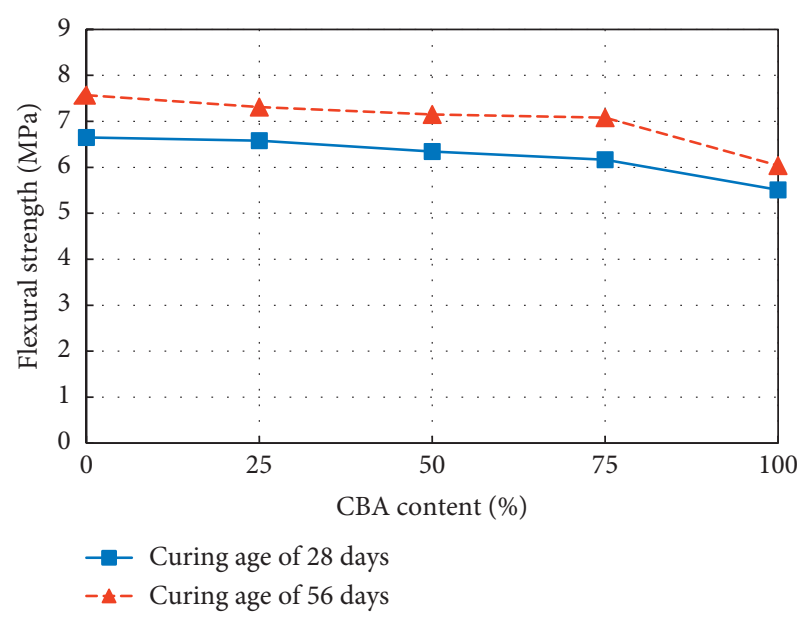

Figure 8: Flexural strength test results.

values of CBA concrete mixtures M25, M50, M75, and M100 were reduced by $3.4,5.5,6.5$, and $20.2 \%$ in comparison with that of the control mixture $(7.6 \mathrm{MPa})$, respectively. The flexural strength difference between the CBA concrete and the control concrete at a curing age of 56 days was quite similar to that at a curing age of 28 days. At both curing ages of 28 and 56 days, compared to the flexural strength of the mixture containing natural fine aggregates only, the reduction in the flexural strength of the mixture containing $100 \%$ CBA fine aggregates was more remarkable than that of mixtures containing 25, 50, and 75\% CBA fine aggregates.

The flexural strength values of the concrete specimens with different curing ages are also shown in Figure 8 . When the curing age increased from 28 to 56 days, the flexural strength values of the concrete containing $0,25,50,75$, and $100 \%$ replacements of fine aggregates by CBA increased by $13.8,11.1,12.7,14.9$, and $9.6 \%$, respectively. The increase in flexural strength of the CBA concrete with increasing curing time primarily resulted from the pozzolanic reaction of the $\mathrm{CBA}$, as described in the earlier section regarding compressive strength.

3.6. Relationship between the Compressive Strength, Splitting Tensile Strength, and Flexural Strength. In this study, to examine the relationship between the different strengths of CBA concrete, a regression analysis was performed. In the regression analysis, the coefficient of determination $\left(R^{2}\right)$, normally ranging from 0 to 1 , represents the goodness of a model fit. An $R^{2}$ value close to 1 indicates that the regression accurately fits the data and vice versa. Regression analysis was performed based on two approaches. The first regression analysis incorporated the test results obtained only in this study, and the second incorporated the test results obtained in this study and in previous studies by using exponential functions.

The relationship between the splitting tensile strength and compressive strength of the CBA concrete under two different curing ages is demonstrated in Figure 9(a). Moreover, the relationship between the splitting tensile strength and compressive strength of the CBA concrete, 
which are based on the test results in this study, is derived by the following equation:

$$
f_{\mathrm{t}}=2.9085 e^{0.0062 f_{\mathrm{c}}}, \quad R^{2}=0.19,
$$

where $f_{\mathrm{t}}$ is the splitting tensile strength $(\mathrm{MPa})$ and $f_{\mathrm{c}}$ is the compressive strength ( $\mathrm{MPa}$ ).

The splitting tensile strength of the CBA concrete was nearly exponentially proportional to that of the compressive strength. The porosity in the concrete matrix derived from replacing fine aggregates with CBA increased, which resulted in decreases in both the compressive strength and the splitting tensile strength of the concrete. However, increasing the curing time led to an increase in both the compressive strength and the splitting tensile strength. The relationship between the splitting tensile strength and compressive strength of the CBA concrete based on the test results in this study and in previous studies $[24,39]$ is shown in Figure 9(b). The compressive strengths of the CBA concrete varied from 15 to $37 \mathrm{MPa}$ in the study by Rafieizonooz et al. [24] and ranged from 40 to $59.5 \mathrm{MPa}$ in the study by Nikbin et al. [39]. The compressive strength values of CBA concrete in previous studies were less than approximately $60 \mathrm{MPa}$, whereas the compressive strength values of the CBA concrete in this study ranged from 63.3 to $76.7 \mathrm{MPa}$, thereby exceeding $60 \mathrm{MPa}$.

The proposed exponential equation used to predict the relationship between the compressive strength and the splitting tensile strength of CBA concrete, as obtained from the test results in this study and in previous studies, is expressed as follows:

$$
f_{\mathrm{t}}=1.6635 e^{0.0175 f_{\mathrm{c}}}, \quad R^{2}=0.66,
$$

where $f_{\mathrm{t}}$ is the splitting tensile strength (MPa) and $f_{\mathrm{c}}$ is the compressive strength ( $\mathrm{MPa})$.

Overall, this equation underestimated the tensile strength values, when the compressive strength values ranged from approximately 40 to $60 \mathrm{MPa}$, whereas it overestimated the tensile strength values, when the compressive strength values ranged from approximately 60 to $80 \mathrm{MPa}$.

The relationship between the flexural strength and compressive strength of the CBA concrete under two different curing ages is shown in Figure 10(a). The flexural strength of the CBA concrete increased as the compressive strength increased. The relationship tendency between the flexural strength and compressive strength of the CBA concrete was similar to that between the splitting tensile strength and compressive strength of the CBA concrete. The relationship between the flexural strength and compressive strength of the CBA concrete, based on the test results in this study, is derived by the following equation:

$$
f_{\mathrm{r}}=1.5192 e^{0.0208 f_{\mathrm{c}}}, \quad R^{2}=0.81,
$$

where $f_{\mathrm{r}}$ is the flexural tensile strength (MPa) and $f_{\mathrm{c}}$ is the compressive strength (MPa).

Rafieizonooz et al. [24] and Nikbin et al. [39] also implemented an experimental program for measuring the flexural strength of concrete containing CBA aggregates. The relationship between the flexural strength and compressive strength of the CBA concrete based on the test results in this study and in their studies is shown in Figure 10(b). An exponential equation for predicting the relationship between the flexural strength and compressive strength of CBA concrete is suggested as follows:

$$
f_{\mathrm{r}}=2.627 e^{0.0151 f_{c}}, \quad R^{2}=0.71,
$$

where $f_{\mathrm{r}}$ is the flexural tensile strength $(\mathrm{MPa})$ and $f_{\mathrm{c}}$ is the compressive strength $(\mathrm{MPa})$.

This equation underestimated the flexural strength values when the compressive strength values ranged from 40 to $60 \mathrm{MPa}$, whereas it overestimated the flexural strength values, when the compressive strength values ranged from 60 to $80 \mathrm{MPa}$.

Finally, the relation between the splitting tensile strength and flexural tensile strength of the CBA concrete under two different curing ages is shown in Figure 11(a). Overall, the splitting tensile strength values of the CBA concrete were nearly proportional to the flexural strength values of the CBA concrete. The relationship equation between the splitting tensile and flexural strength of the CBA concrete, based on the test results in this study, is proposed by the following equation:

$$
f_{\mathrm{t}}=3.3715 e^{0.0436 f_{\mathrm{r}}}, \quad R^{2}=0.21,
$$

where $f_{\mathrm{t}}$ is the splitting tensile strength $(\mathrm{MPa})$ and $f_{\mathrm{r}}$ is the flexural tensile strength (MPa).

The relationship between the splitting tensile strength and flexural tensile strength of the CBA concrete based on the test results in this study and in previous studies $[24,39]$ is shown in Figure 11(b). An exponential equation for predicting the splitting tensile strength of the CBA concrete by using the flexural strength is suggested as follows:

$$
f_{\mathrm{t}}=1.2717 e^{0.195 f_{\mathrm{r}}}, \quad R^{2}=0.64,
$$

where $f_{\mathrm{t}}$ is the splitting tensile strength $(\mathrm{MPa})$ and $f_{\mathrm{r}}$ is the flexural tensile strength (MPa).

3.7. Ultrasonic Pulse Velocity. The ultrasonic pulse velocity experimental results of concrete specimens with different CBA contents are illustrated in Figure 12. At a curing age of 28 days, the ultrasonic velocities of the CBA concrete mixtures M25, M50, M75, and M100 were reduced by 0.4 , $0.9,2.1$, and $2.7 \%$ compared to the control mixture M00, respectively. At a curing age of 56 days, the ultrasonic velocities of CBA concrete mixtures M25, M50, M75, and M100 were also reduced by $0.9,1.4,2.1$, and $2.6 \%$ compared to that of the control mixture M00, respectively. Ultrasonic pulse waves pass faster through a solid body than through space [40]. Hence, increases in the void content of the CBA aggregate might cause a decrease in the ultrasonic pulse velocity. Moreover, when the curing age increased from 28 to 56 days, the ultrasonic velocities of the CBA concrete mixtures with CBA fine aggregate contents of $0,25,50,75$, and $100 \%$ increased by $1.0,0.5,0.5,1.0$, and $1.1 \%$, respectively. Therefore, the test results indicated that the ultrasonic 


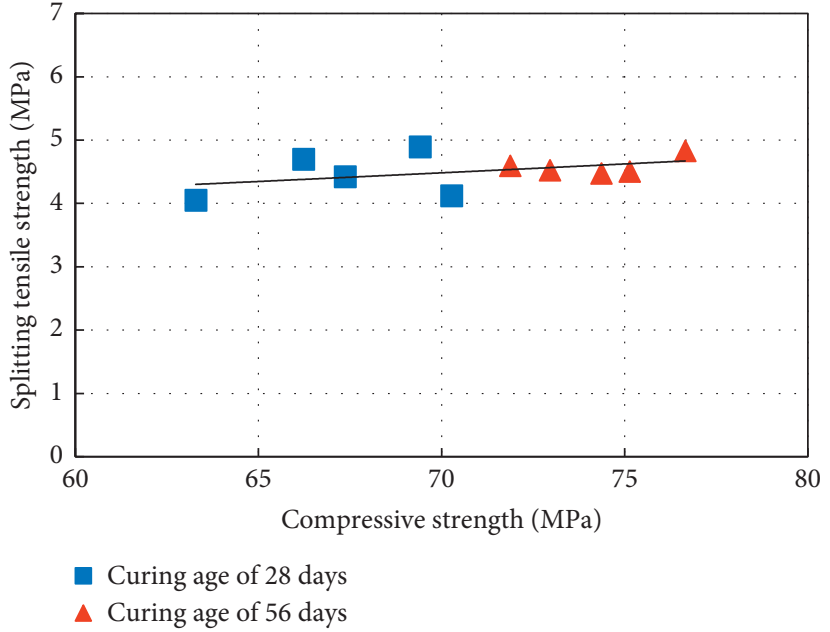

(a)

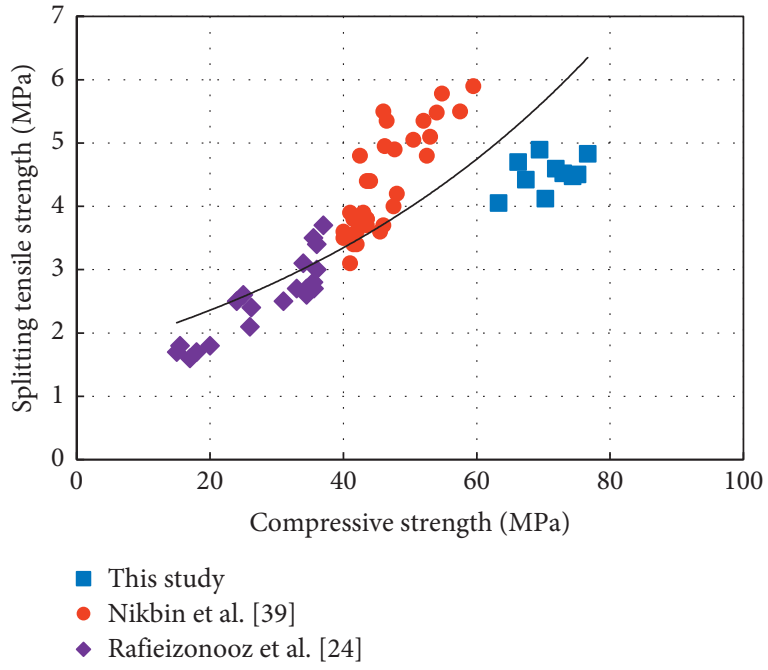

(b)

Figure 9: Relationship between the splitting tensile strength and compressive strength. (a) Test results in this study. (b) Test results in this study and previous studies.

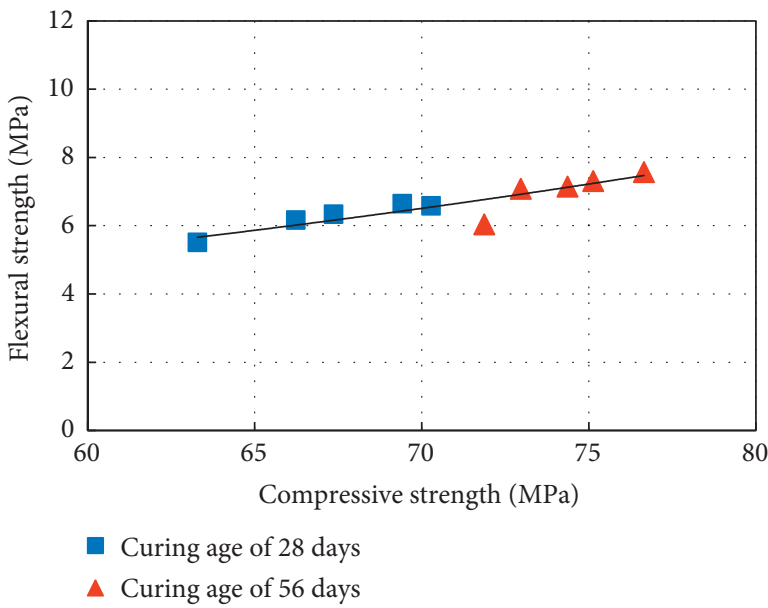

(a)

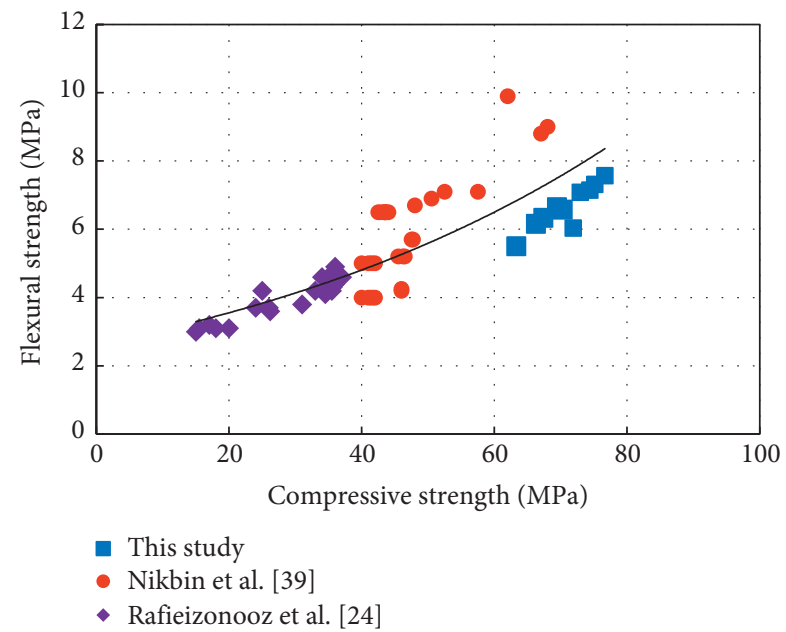

(b)

Figure 10: Relationship between the flexural strength and compressive strength. (a) Test results in this study. (b) Test results in this study and previous studies.

pulse velocities of the CBA concrete mixtures decreased with increasing CBA content but slightly increased with increasing curing age.

The relationship between the compressive strength and ultrasonic pulse velocity of the CBA concrete obtained in this study is shown in Figure 13(a). As expected, the overall compressive strength of the CBA concrete increased as the ultrasonic pulse velocity of the CBA concrete increased. The relationship between the compressive strength and the ultrasonic pulse velocity of the CBA concrete is shown in Figure 13(b), in which the test results in this study and in other studies $[18,24]$ are included. The measured values in this study and those in the existing studies represented significant deviations. This phenomenon might be due to the difference between the chemical components of the CBA used in this study and those in the existing studies. By using these test results, an equation for predicting the relationship between the compressive strength and the ultrasonic pulse velocity of the CBA concrete is suggested as follows:

$$
f_{\mathrm{c}}=0.6968 e^{0.001 \mathrm{~V}}, \quad R^{2}=0.17
$$

where $f_{\mathrm{c}}$ is the compressive strength (MPa) and $V$ is the ultrasonic pulse velocity $(\mathrm{m} / \mathrm{s})$.

As expected, the coefficient of determination $\left(R^{2}\right)$ in (4) was not high, meaning that the relationship between the test results and predictions was not good because there were significant deviations between the test results in this study and those in the existing studies, as shown in Figure 13(b). 


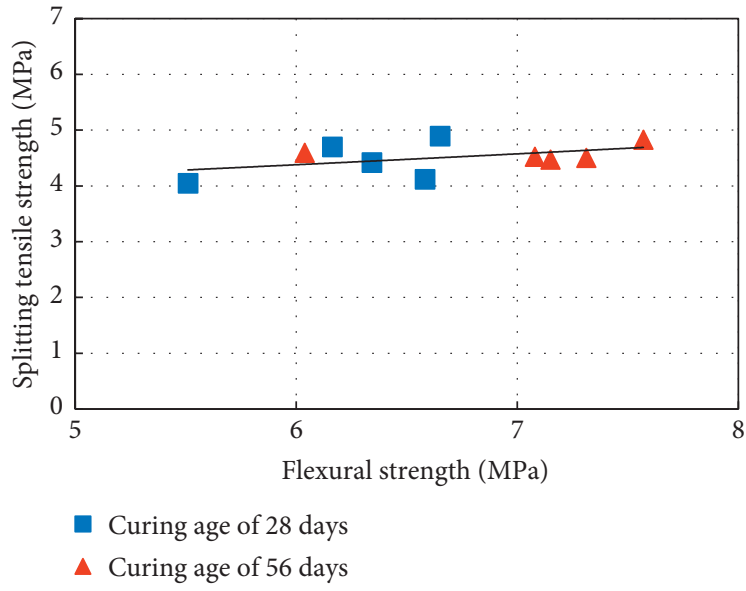

(a)

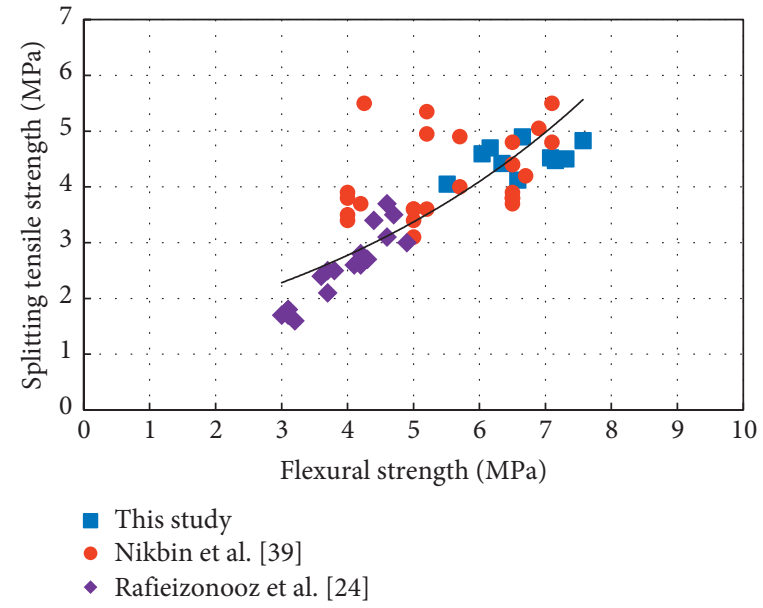

(b)

FIGURE 11: Relationship between the splitting tensile strength and flexural strength. (a) Test results in this study. (b) Test results in this study and previous studies.

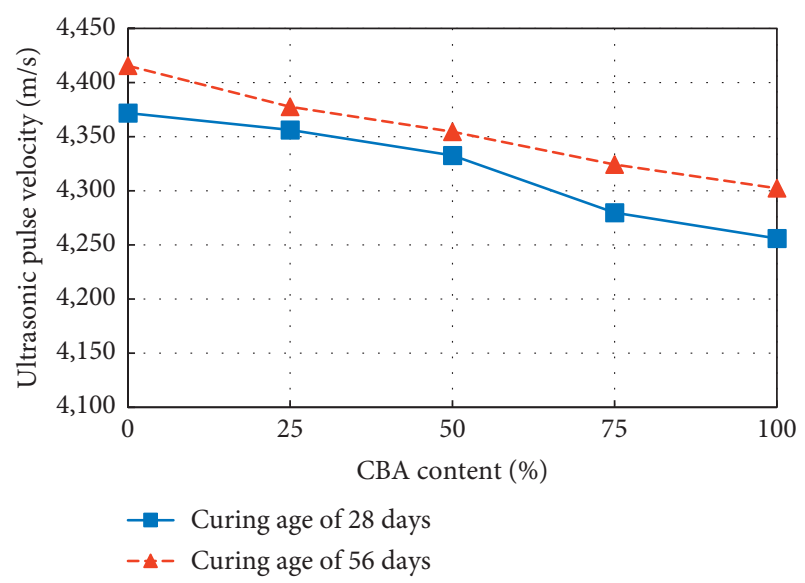

FIGURE 12: Ultrasonic pulse velocity test results.

Figure 14(a) shows the relationship between the splitting tensile strength and ultrasonic pulse velocity of the CBA concrete obtained in the study. As the ultrasonic pulse velocity increased, both the compressive strength and the splitting tensile strength of the CBA concrete increased.

The relationship between the splitting tensile strength and the ultrasonic pulse velocity of the CBA concrete is shown in Figure 14(b), in which the test results in this study and in another study [24] are included. By using these test results, an equation for predicting the relationship between the splitting tensile strength and the ultrasonic pulse velocity of the CBA concrete is suggested as follows:

$$
f_{\mathrm{t}}=0.0004 e^{0.0021 V}, \quad R^{2}=0.71,
$$

where $f_{\mathrm{t}}$ is the splitting tensile strength $(\mathrm{MPa})$ and $V$ is the ultrasonic pulse velocity $(\mathrm{m} / \mathrm{s})$.

In the figure, there are some deviations in predicting the splitting tensile strength when the ultrasonic pulse velocities were between approximately 4200 and $4500 \mathrm{~m} / \mathrm{s}$. The predictions underestimated the measurements in this study but overestimated the measurements in the other study.

Finally, the relationship between the flexural strength and ultrasonic pulse velocity of the CBA concrete measured in this study is shown in Figure 15(a). The CBA concrete flexural strength was closely related to the ultrasonic pulse velocity.

The relationship between the flexural strength and the ultrasonic pulse velocity of the CBA concrete is shown in Figure 15(b), in which the test results in this study and in another study [24] are also included. An equation for predicting the relationship between the flexural strength and the ultrasonic pulse velocity of the CBA concrete is suggested as follows:

$$
f_{\mathrm{r}}=0.0062 e^{0.0016 \mathrm{~V}}, \quad R^{2}=0.59,
$$

where $f_{\mathrm{r}}$ is the flexural strength $(\mathrm{MPa})$ and $V$ is the ultrasonic pulse velocity $(\mathrm{m} / \mathrm{s})$.

As the predictions underestimated the splitting tensile strength values of the CBA concrete, which were measured in this study, the predictions also underestimated the flexural strength values of the CBA concrete, which were measured in this study. These phenomena occurred because the splitting tensile strength of the CBA concrete was related to the flexural strength, as shown in Figures 11(a) and 11(b).

\section{Conclusions}

The strength properties of CBA concrete with compressive strength values greater than $60 \mathrm{MPa}$ were investigated in this study. Based on the extensive experimental results, the following conclusions can be drawn:

(1) The test results showed that, at low CBA contents, the unit weight of the HSC concrete slightly reduced by approximately $2 \%-3 \%$. These results implied that low CBA contents could be applied to fabricate HSC with a normal weight. 


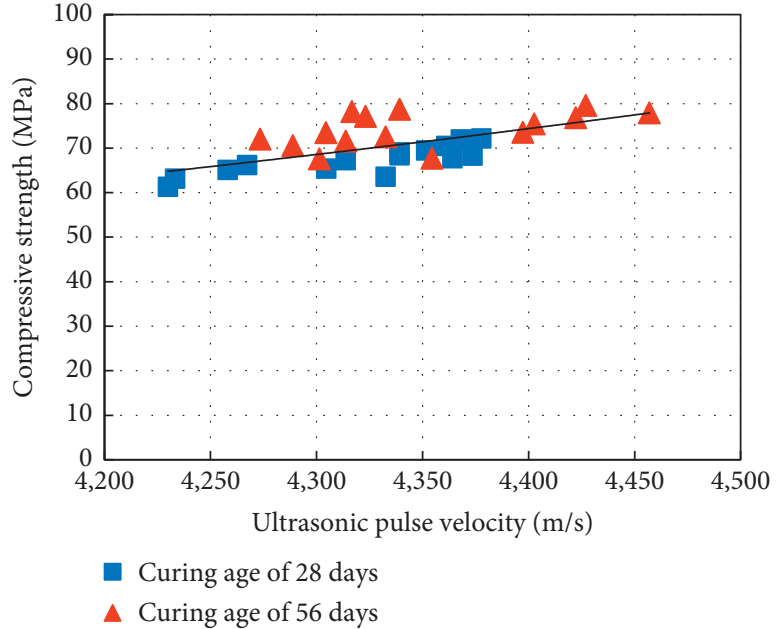

(a)

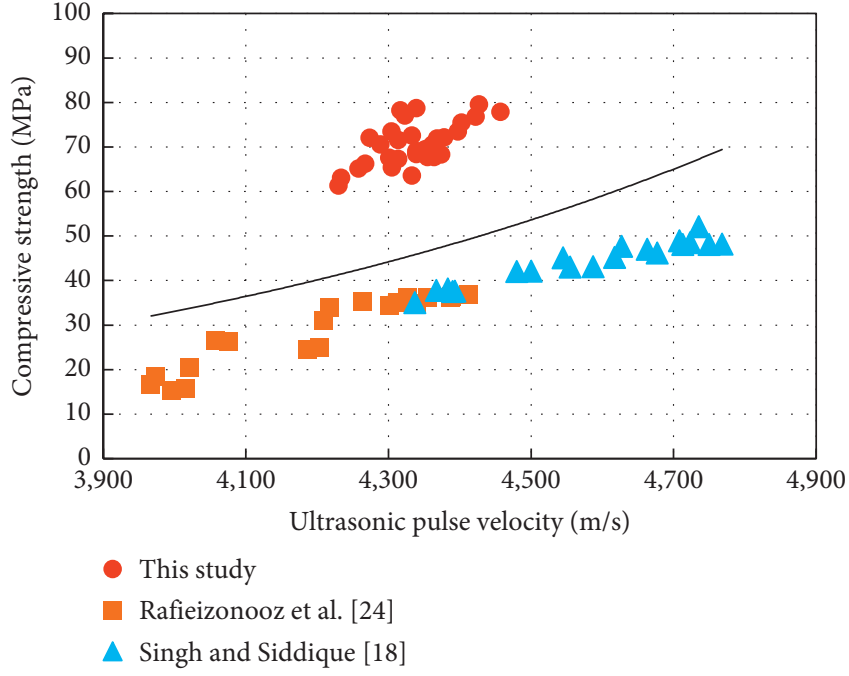

(b)

FIGURE 13: Relationship between the compressive strength and ultrasonic pulse velocity. (a) Test results in this study. (b) Test results in this study and previous studies.

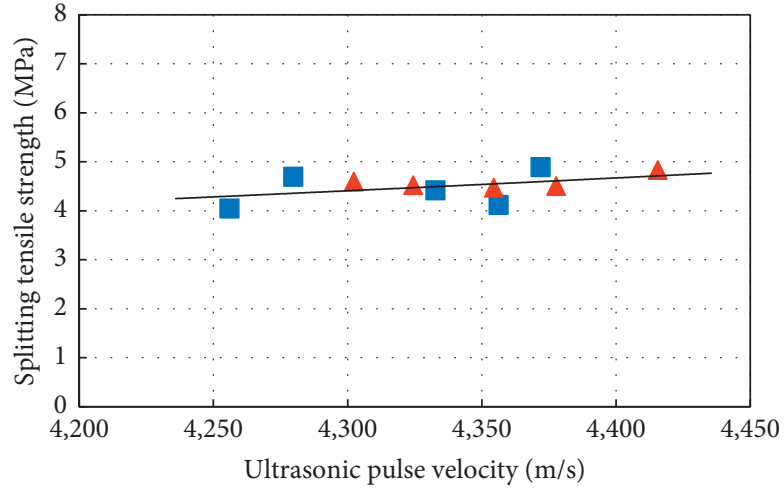

- Curing age of 28 days

$\Delta$ Curing age of 56 days

(a)

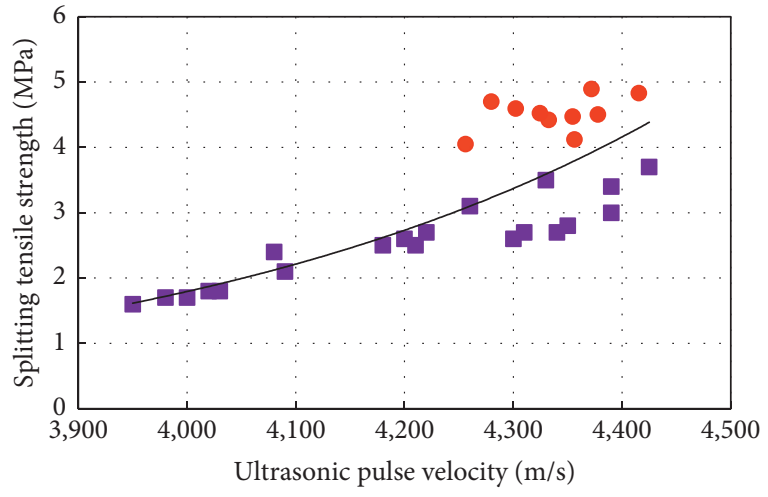

- This study

- Rafieizonooz et al. [24]

FIGURE 14: Relationship between the splitting tensile strength and ultrasonic pulse velocity. (a) Test results in this study. (b) Test results in this study and previous study.

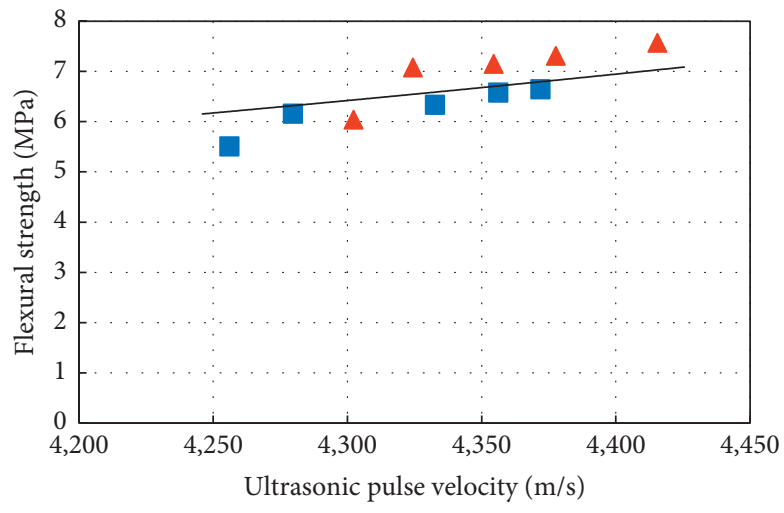

- Curing age of 28 days

$\Delta$ Curing age of 56 days

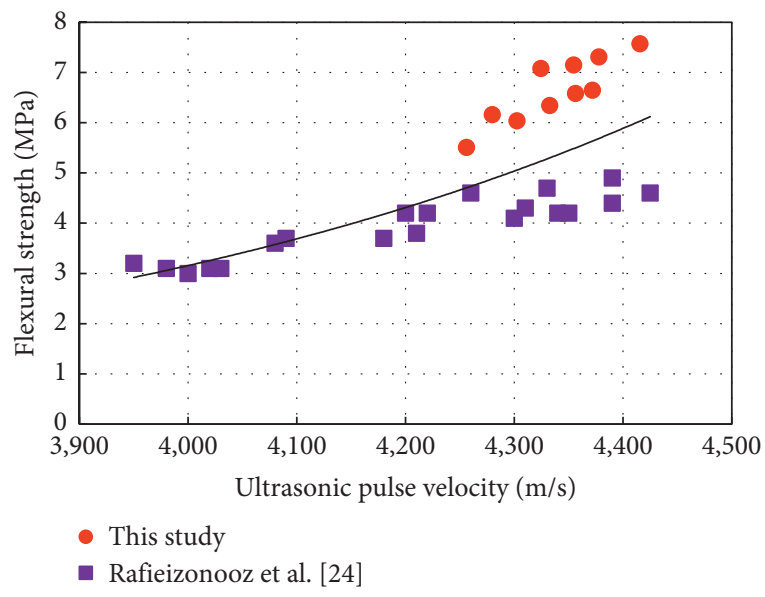

(b)

FIGURE 15: Relationship between the flexural strength and ultrasonic pulse velocity. (a) Test results in this study. (b) Test results in this study and previous study. 
(2) For the CBA concrete, even if it contained total replacement for fine aggregates, the compressive strength exceeded $60 \mathrm{MPa}$. The test results implied that the CBA concrete possibly reached the level of HSC. Therefore, CBA could be utilized for fabricating HSC as a partial or total substitution for fine aggregates.

(3) Overall, replacing fine aggregates by CBA insignificantly affected the splitting tensile strength of the HSC. Particularly, at the curing age of 56 days, the splitting tensile strengths of HSC including CBA slightly reduced at the various CBA contents. However, clear reducing tendencies were observed in the flexural strengths of the CBA concrete mixtures at the curing age of 28 and 56 days.

(4) The experimental results showed that the ultrasonic pulse velocity of the HSC specimens with various CBA contents reduced by approximately $3 \%$. This phenomenon indicated that the density of the HSC specimens decreased. Accordingly, utilizing CBA as fine aggregates in HSC would reduce the concrete strength. The test results actually showed that the strengths of the CBA concrete decreased as the ultrasonic pulse velocity of the CBA concrete decreased.

(5) Equations to predict the compressive strength, splitting tensile strength, and flexural strength of the CBA concrete by using the ultrasonic pulse velocity were suggested. The coefficient of determination in predicting the strengths of the CBA concrete was not high because the measurements in this study and in previous studies were scattered. Therefore, further extensive experimental studies are needed to improve the accuracy of the predictions.

\section{Data Availability}

The data used to support the findings of this study are available from the corresponding author upon request.

\section{Conflicts of Interest}

The authors declare that they have no conflicts of interest regarding the publication of this manuscript.

\section{Acknowledgments}

This research was supported by the Ministry of Trade, Industry and Energy (MOTIE) and the Korea Institute of Energy Research (KETEP) (no. 20181110200070).

\section{References}

[1] S. Oruji, N. A. Brake, R. K. Guduru et al., "Mitigation of ASR expansion in concrete using ultra-fine coal bottom ash," Construction and Building Materials, vol. 202, pp. 814-824, 2019.
[2] T. Çiçek and Y. Çinçin, "Use of fly ash in production of lightweight building bricks," Construction and Building Materials, vol. 94, pp. 521-527, 2015.

[3] A. Abdulmatin, W. Tangchirapat, and C. Jaturapitakkul, "An investigation of bottom ash as a pozzolanic material," Construction and Building Materials, vol. 186, pp. 155-162, 2018.

[4] H.-K. Kim, "Utilization of sieved and ground coal bottom ash powders as a coarse binder in high-strength mortar to improve workability," Construction and Building Materials, vol. 91, pp. 57-64, 2015.

[5] S. Oruji, N. A. Brake, L. Nalluri, and R. K. Guduru, "Strength activity and microstructure of blended ultra-fine coal bottom ash-cement mortar," Construction and Building Materials, vol. 153, pp. 317-326, 2017.

[6] A. R. K. Gollakota, V. Volli, and C.-M. Shu, "Progressive utilisation prospects of coal fly ash: a review," Science of the Total Environment, vol. 672, pp. 951-989, 2019.

[7] V. Bruder-Hubscher, F. Lagarde, M. J. F. Leroy, C. Coughanowr, and F. Enguehard, "Utilisation of bottom ash in road construction: a lysimeter study," Waste Management \& Research, vol. 19, no. 6, pp. 557-566, 2001.

[8] M. E. Munawer, "Human health and environmental impacts of coal combustion and post-combustion wastes," Journal of Sustainable Mining, vol. 17, no. 2, pp. 87-96, 2018.

[9] S. Jung and S.-J. Kwon, "Engineering properties of cement mortar with pond ash in South Korea as construction materials: from waste to concrete," Central European Journal of Engineering, vol. 3, pp. 522-533, 2013.

[10] N. Singh, Shehnazdeep, and A. Bhardwaj, "Reviewing the role of coal bottom ash as an alternative of cement," Construction and Building Materials, vol. 233, Article ID 117276, 2020.

[11] N. Singh, P. Kumar, and P. Goyal, "Reviewing the behaviour of high volume fly ash based self compacting concrete," Journal of Building Engineering, vol. 26, Article ID 100882, 2019.

[12] C. Argiz, A. Moragues, and E. Menéndez, "Use of ground coal bottom ash as cement constituent in concretes exposed to chloride environments," Journal of Cleaner Production, vol. 170 , pp. $25-33,2018$.

[13] H. K. Kim and H. K. Lee, "Coal bottom ash in field of civil engineering: a review of advanced applications and environmental considerations," KSCE Journal of Civil Engineering, vol. 19, no. 6, pp. 1802-1818, 2015.

[14] S. Pal, M. Shariq, H. Abbas, A. K. Pandit, and A. Masood, "Strength characteristics and microstructure of hooked-end steel fiber reinforced concrete containing fly ash, bottom ash and their combination," Construction and Building Materials, vol. 247, Article ID 118530, 2020.

[15] Korea Environment Institute (KEI), Minimizing Environmental Impact of Ash Treatment in Thermal Power Plants, Korea Environment Institute, Seoul, Republic of Korea, 2019.

[16] N. Singh, M. Mithulraj, and S. Arya, "Influence of coal bottom ash as fine aggregates replacement on various properties of concretes: a review," Resources, Conservation and Recycling, vol. 138, pp. 257-271, 2018.

[17] L. B. Andrade, J. C. Rocha, and M. Cheriaf, "Influence of coal bottom ash as fine aggregate on fresh properties of concrete," Construction and Building Materials, vol. 23, no. 2, pp. 609614, 2009.

[18] M. Singh and R. Siddique, "Properties of concrete containing high volumes of coal bottom ash as fine aggregate," Journal of Cleaner Production, vol. 91, pp. 269-278, 2015.

[19] J. W. Bang, G. Ganesh Prabhu, Y. I. Jang, and Y. Y. Kim, "Development of ecoefficient engineered cementitious 
composites using supplementary cementitious materials as a binder and bottom ash aggregate as fine aggregate," International Journal of Polymer Science, vol. 2015, Article ID 681051, 12 pages, 2015.

[20] M. Singh and R. Siddique, "Effect of coal bottom ash as partial replacement of sand on workability and strength properties of concrete," Journal of Cleaner Production, vol. 112, pp. 620630, 2016.

[21] N. Singh, M. Mithulraj, and S. Arya, "Utilization of coal bottom ash in recycled concrete aggregates based self compacting concrete blended with metakaolin," Resources, Conservation and Recycling, vol. 144, pp. 240-251, 2019.

[22] I.-H. Yang and J. Park, "A study on the thermal properties of high-strength concrete containing CBA fine aggregates," Materials, vol. 13, no. 7, p. 1493, 2020.

[23] M. Singh and R. Siddique, "Strength properties and microstructural properties of concrete containing coal bottom ash as partial replacement of fine aggregate," Construction and Building Materials, vol. 50, pp. 246-256, 2014.

[24] M. Rafieizonooz, J. Mirza, M. R. Salim, M. W. Hussin, and E. Khankhaje, "Investigation of coal bottom ash and fly ash in concrete as replacement for sand and cement," Construction and Building Materials, vol. 116, pp. 15-24, 2016.

[25] S. B. Park, Y. I. Jang, J. Lee, and B. J. Lee, "An experimental study on the hazard assessment and mechanical properties of porous concrete utilizing coal bottom ash coarse aggregate in Korea," Journal of Hazardous Materials, vol. 166, no. 1, pp. 348-355, 2009.

[26] C. Ngohpok, V. Sata, T. Satiennam, P. Klungboonkrong, and P. Chindaprasirt, "Mechanical properties, thermal conductivity, and sound absorption of pervious concrete containing recycled concrete and bottom ash aggregates," KSCE Journal of Civil Engineering, vol. 22, no. 4, pp. 1369-1376, 2018.

[27] W. Wongkeo, P. Thongsanitgarn, K. Pimraksa, and A. Chaipanich, "Compressive strength, flexural strength and thermal conductivity of autoclaved concrete block made using bottom ash as cement replacement materials," Materials \& Design, vol. 35, pp. 434-439, 2012.

[28] M. H. W. Ibrahim, A. F. Hamzah, N. Jamaluddin, P. J. Ramadhansyah, and A. M. Fadzil, "Split tensile strength on self-compacting concrete containing coal bottom ash," Procedia-Social and Behavioral Sciences, vol. 195, pp. 2280-2289, 2015.

[29] B. Lai, J. Y. R. Liew, and A. L. Hoang, "Behavior of high strength concrete encased steel composite stub columns with C130 concrete and S690 steel," Engineering Structures, vol. 200, p. 109743, 2019.

[30] B. Lai, J. Y. R. Liew, and M. Xiong, "Experimental study on high strength concrete encased steel composite short columns," Construction and Building Materials, vol. 228, Article ID 116640, 2019.

[31] M. F. Sulaiman, C.-K. Ma, N. M. Apandi et al., "A review on bond and anchorage of confined high-strength concrete," Structures, vol. 11, pp. 97-109, 2017.

[32] H. K. Kim and H. K. Lee, "Use of power plant bottom ash as fine and coarse aggregates in high-strength concrete," Construction and Building Materials, vol. 25, no. 2, pp. 1115-1122, 2011.

[33] Korea Industrial Standard, Standard Test Method for Compressive Strength of Concrete; KS F 2405, Korea Industrial Standards, Seoul, Repubic of Korea, 2010.

[34] Korea Industrial Standard, Standard Test Method for Compressive Strength of Concrete; KS F 2423, Korea Industrial Standards, Seoul, Republic of Korea, 2016.
[35] Korea Industrial Standard, Standard Test Method for Compressive Strength of Concrete; KS F 2408, Korea Industrial Standards, Seoul, Republic of Korea, 2016.

[36] American Society for Testing and Materials (ASTM), Standard Test Method for Pulse Velocity through Concrete; ASTM C597-02, ASTM, West Conshohocken, PA, USA, 2002.

[37] K. Muthusamy, M. H. Rasid, G. A. Jokhio, A. Mokhtar Albshir Budiea, M. W. Hussin, and J. Mirza, "Coal bottom ash as sand replacement in concrete: a review," Construction and Building Materials, vol. 236, Article ID 117507, 2020.

[38] M. Singh and R. Siddique, "Compressive strength, drying shrinkage and chemical resistance of concrete incorporating coal bottom ash as partial or total replacement of sand," Construction and Building Materials, vol. 68, pp. 39-48, 2014.

[39] I. M. Nikbin, S. Rahimi, H. Allahyari, and M. Damadi, "A comprehensive analytical study on the mechanical properties of concrete containing waste bottom ash as natural aggregate replacement," Construction and Building Materials, vol. 121, pp. 746-759, 2016.

[40] E. Baite, A. Messan, K. Hannawi, F. Tsobnang, and W. Prince, "Physical and transfer properties of mortar containing coal bottom ash aggregates from Tefereyre (Niger)," Construction and Building Materials, vol. 125, pp. 919-926, 2016. 